\title{
The Spatial Spillover Effect of Input and Output of Scientific Progress on Regional Economic Growth: The Case of Guangdong Province
}

\author{
Zicheng Huang \\ Department of Statistics, Jinan University, Guangzhou, China \\ Email: zicheng6027@outlook.com
}

How to cite this paper: Huang, Z.C. (2020) The Spatial Spillover Effect of Input and Output of Scientific Progress on Regional Economic Growth: The Case of Guangdong Province. Open Journal of Statistics, 10, 540-553.

https://doi.org/10.4236/ojs.2020.103032

Received: May 28, 2020

Accepted: June 21, 2020

Published: June 24, 2020

Copyright ( 2020 by author(s) and Scientific Research Publishing Inc. This work is licensed under the Creative Commons Attribution International License (CC BY 4.0). http://creativecommons.org/licenses/by/4.0/

\begin{abstract}
This paper makes an empirical analysis of the spatial spillover effect of regional economic growth by using Moran's I and Spatial Durbin Model to study the input and output of technological progress, with the panel data of 21 prefecture-level cities in Guangdong Province from 2008 to 2017. The empirical results show that the spatial autocorrelation exists in the economic development of Guangdong Province, and both the input and output of scientific research innovation have a significant positive effect on the regional economic growth. Under the spatial contiguity weights matrix, the output of scientific research and innovation has a more obvious spillover effect on the economic growth of neighboring cities than the input of scientific research and innovation.
\end{abstract}

\section{Keywords}

Regional Economic Growth, Spatial Spillover Effect, Spatial Durbin Model

\section{Introduction}

Since Economic Reform and open up, China's regional economic development is mainly concentrated in the eastern coastal areas. Guangdong province, backed by Hong Kong and Macao which are multifunctional international centers, becomes China's largest province in the economic field and ranks the first in terms of GDP in China by virtue of its superior geographical location. With the early policy support, Guangdong Province to attract foreign investment, providing a large number of inexpensive land and labor to drive economic growth. However, with the increase of economic aggregate, the growth rate has declined, and Guangdong Province has transformed from the stage of high-speed growth to 
the stage of high-quality development. Among them, scientific and technological innovation is the internal driving force for the further growth of regional economy. At present, many scholars have realized the positive effect of technological innovation on regional economy, and can quantify the technological innovation capacity between different regions. However, the existing literature mostly takes the input of scientific and technological innovation and economic growth rate as the research focus, ignoring the competition of scientific and technological innovation between neighboring regions will increase the investment of funds. The space spillover effect makes it easy to underestimate the impact of technological innovation on the quality of regional economic development. Therefore, this paper takes 21 cities in Guangdong Province as an example, uses the panel data from 2008 to 2017, and adopts the Spatial Durbin Model to study the spatial spillover effect of input and output of scientific and technological innovation on regional economic growth.

In fact, domestic and foreign scholars have done a lot of research on regional economic growth with regard to technological progress, which has laid a solid foundation for the following empirical analysis. New economic geography puts forward the spatial dimension on the basis of classical economics, and analyzes economic growth from the perspective of space. Lucas [1] proposed the concept of spatial spillover effect. Krugman [2] combined the assumptions of imperfect competition and increasing returns to scale, which brought the study of regional economics into a new dimension. Englmann [3] and Kubo [4] also pointed out that the spillover effects of regional economic growth include global spatial spillover effect and local spatial spillover effect, respectively. Viladecansmarsal [5] used the model of spatial econometric to study the spatial spillover effect between Spanish cities, and found that the increase in the population size and employment level of neighboring cities would strengthen the economic agglomeration of the place. Avijit and Niranjan [6] based on data from 1981-2007 in northeastern India, tested the local NDP with significant spillover effects, and the growth in most regions was higher than the regional average. Marco [7] considered that the core cities in the urban agglomeration have a spatial spillover effect on peripheral cities, and used panel data from 30 provinces in China to examine the effect of labor on economic growth in different regions of China, and concluded that the spillover effect of human capital leads to the agglomeration effect of economic growth.

In the study of the impact of scientific research innovation on regional economic growth, Benjamin and Marcos [8] considered that there is a competitive effect between the investment of $\mathrm{R} \& \mathrm{D}$ expenditures between countries, and policy incentives can promote the active interflow of private scientific research enterprises between countries. Qin [9] et al. based on Chinese provinces and concluded that the efficiency of inter-provincial innovation output has a strong spatial dependence and exhibits a two-way spillover effect. Kristy [10] et al. found that scientific research laboratories and talents in the United States are also spatially concentrated, mainly in economically developed regions. Rouholah 
[11] et al. used Iran as an example to analyze the inefficient technological innovation ability which has a negative effect on economic growth. Zhou [12] et al. studied the impact of technological growth on government expenditure and found that the more investment in science and technology research, the higher the economic growth, the lower the macro-control effect of government expenditure. Zhang [13] found that spillovers caused by foreign direct investment had a positive and statistically significant impact on the productivity of Chinese innovation activities. Chen [14] et al. divided China into eight regions and discussed the issues of GDP, R \& D expenditures and patents. Xiong [15] et al. concluded that the level of society played a coordinated role in the simultaneous development of technological innovation output and economic development.

In summary, technological progress is a new endogenous driving force for regional economic development. Studying the spatial spillover effect of technological progress in Guangdong Province is of great significance to the economic development and transformation of Guangdong Province. This paper will conduct research based on the following three aspects: first, study the spatial autocorrelation of the economy in Guangdong province. Second, choose the input and output of scientific research and innovation as explanatory variables, and at the same time select relevant control variables to construct a spatial econometric model. Third, empirical analysis based on the above spatial econometric model, to explore the specific effect of technological progress input and output on economic growth.

\section{Research Methods and Data Sources}

\subsection{The Moran's I}

The spatial autocorrelation test is used to determine whether there is a spatial spillover effect between cities. The Moran's I is the most common method. The Moran's I is divided into a global Moran's I and a local Moran's I. The former was proposed by Australian statistician Moran in 1950, and the latter was proposed by American professor Luc Anselin. The global Moran's I is used to test the spatial correlation between spatial units and reflect the similarity of each geographic unit in the study area with other nearby geographic units. Its definition is:

$$
I=\frac{\sum_{i=1}^{n} \sum_{j=1}^{n} w_{i j}\left(x_{i}-\bar{x}\right)\left(x_{j}-\bar{x}\right)}{S^{2} \sum_{i=1}^{n} \sum_{j=1}^{n} w_{i j}}
$$

$S^{2}$ is the sample variance, $\bar{x}$ is the sample mean, $w_{i j}$ is the spatial weight matrix element that describes the spatial relationship between area $i$ and area $j$, and $n$ is the number of spatial units in the area. The value of the global Moran's I is between $(-1,1)$, less than 0 means that the whole area is negatively spatially correlated, more than 0 means that the area is positively spatially correlated, and equal to 0 means that there is no spatial correlation. The larger the absolute value, 
the higher the spatial correlation.

The local Moran's I is used to test whether there is spatial agglomeration in local areas. For any spatial unit $i$, the formula for calculating the local Moran's I is:

$$
I_{i}=\frac{1}{S^{2}}\left(x_{i}-\bar{x}\right) \sum_{j, j \neq i}^{n} w_{i j}\left(x_{j}-\bar{x}\right)
$$

when $I_{i}$ is more than 0 , the spatial correlation of area $i$ may be high-high or low-low association type. The high-high type is the area $i$ whose attribute value is higher than the mean is the neighboring area whose attribute value is higher than the mean. The low-low type is that the area $i$ whose attribute value is lower than the average is surrounded by the adjacent area whose attribute value is lower than the average. When $I_{i}$ is less than 0 , the spatial correlation of area $i$ may be high-low or low-high association type. The high-low type is the area $i$ with the attribute value higher than the mean is the neighboring area with the attribute value lower than the mean. The low-high type is that the area $i$ whose attribute value is lower than the average is surrounded by the adjacent area whose attribute value is higher than the average. When $I_{i}$ is close to 0 , it means that there is no spatial association between this area and the adjacent area.

\subsection{Setting of Spatial Weight Matrix}

Because technological innovation requires excellent infrastructure and strong economic capital, the cooperation and competition between technological innovation in cities with similar economic strength will be stronger. It means the corresponding spillover effect will be more obvious. Taking into account the geographical environment and the actual situation of Guangdong Province, this paper uses traditional spatial contiguity matrix and economic distance weight matrix for testing. Spatial contiguity matrix means that the contiguity weight between two cities is 1 , otherwise it is 0 . The formula of the economic distance weight matrix is as follows:

$$
w_{i j}=\frac{1}{\left|Y_{i}-Y_{j}\right|}, i \neq j
$$

when $i=j$, the spatial weight is 0 , and $Y$ refers to the Real GDP per capita of the city during the sample period.

\subsection{Spatial Durbin Model}

The empirical part of this paper uses panel data and Spatial Autoregressive Model. The Spatial Autoregressive Model is mainly divided into Spatial Lag Model, Spatial Error Model and Spatial Durbin Model. Among them, the first two are special forms of the Spatial Durbin Model, so this article uses the Spatial Durbin Model, the general form is as follows:

$$
Y=\rho w Y+X \beta+\theta w X+\varepsilon, \varepsilon \sim N\left(0, \sigma^{2} I_{n}\right)
$$

where $\rho$ is the spatial autocorrelation coefficient, $w$ is the spatial weight matrix, 
$\beta$ and $\theta$ are the coefficients of the spatial lag term of the explanatory variable and the spatial lag term of the explanatory variable, and $\varepsilon$ is the random error term.

\subsection{Panel Data Sources}

This paper refers to the research in the relevant papers and uses the Real GDP per capita of each city as the explanatory variable to measure the economic development level of each city, while avoiding the effect of population size. This paper focuses on the effect of the input and output of technological innovation on regional economic growth, taking into account the practical role of scientific and technological innovation on social production, so the $\mathrm{R} \& \mathrm{D}$ expenditure of the whole society of the city in that year is taken as the index of input, and the number of urban patent authorization in that year is taken as the index of output. Considering the many reasons that affect regional economic growth and the actual situation in Guangdong Province, the control variables mainly describe the effects of assets, labor, industrial structure, urbanization level, macro-control capacity and open-up level on economic growth. Assets are invested in fixed assets as an indicator, the labor uses employees at the end of the year as the indicator, the industrial structure is the ratio of the output value of the tertiary industry to the GDP of the year, the urbanization level uses the ratio of the urban household registration to the total population, and the macro-control capacity is based on the government expenditure budget. The open-up level is foreign direct investment as an indicator. The above data comes from "Guangdong Statistical Yearbook", "Guangdong Science and Technology Statistical Yearbook" and statistical bulletins of various cities.

\section{Moran's I Test}

\subsection{Global Moran's I Test}

After constructing the two spatial weight matrices, the global Moran's I test was conducted on the Real GDP per capita of 21 prefecture-level cities in Guangdong Province from 2008 to 2017. The results are shown in Table 1. The results show that both spatial matrices indicate that there is a positive spatial correlation between the regional economic development capabilities of 21 prefecture-level cities in Guangdong Province. Among them, the spatial contiguity matrix has a larger Moran's I at a significance level of 0.01 , which can explain the spatial spillover effect of the region. Therefore, later research uses spatial contiguity matrix for empirical analysis.

\subsection{Local Moran's I Test}

After the global Moran's I test, in order to deepen the spatial correlation of the regional economic development level between cities in Guangdong Province, based on the data of 2008 and 2017, the spatial contiguity matrix was used to calculate the local Moran's I. The results are shown in Table 2. Figure 1 is divided into 
Table 1. Global Moran's I of two spatial weight matrices.

\begin{tabular}{ccccc}
\hline \multirow{2}{*}{ year } & \multicolumn{2}{c}{ spatial contiguity matrix } & \multicolumn{2}{c}{ economic distance weight matrix } \\
\cline { 2 - 5 } & Moran's I & $p$ & Moran's I & $p$ \\
\hline 2008 & 0.391 & 0.00 & 0.069 & 0.10 \\
2009 & 0.375 & 0.00 & 0.071 & 0.10 \\
2010 & 0.37 & 0.00 & 0.067 & 0.10 \\
2011 & 0.37 & 0.00 & 0.072 & 0.10 \\
2012 & 0.353 & 0.00 & 0.082 & 0.08 \\
2013 & 0.339 & 0.00 & 0.082 & 0.08 \\
2014 & 0.326 & 0.00 & 0.08 & 0.08 \\
2015 & 0.327 & 0.00 & 0.08 & 0.08 \\
2016 & 0.337 & 0.00 & 0.077 & 0.09 \\
2017 & 0.343 & 0.00 & 0.076 & 0.09 \\
\hline
\end{tabular}

Table 2. The spatial agglomeration types of the economic development level of 21 cities.

\begin{tabular}{|c|c|c|c|c|}
\hline year & High-high & Low-high & Low-low & High-low \\
\hline 2008 & $\begin{array}{l}\text { Guangzhou, Shenzhen, } \\
\text { Foshan, Dongguan, } \\
\text { Zhuhai, Zhongshan }\end{array}$ & $\begin{array}{l}\text { Huizhou, Jiangmen, } \\
\text { Qingyuan, Zhaoqing, } \\
\text { Shaoguan }\end{array}$ & $\begin{array}{l}\text { Chaozhou, Heyuan, Jieyang, } \\
\text { Maoming, Meizhou, Shantou, } \\
\text { Shanwei, Yangjiang, Yunfu, } \\
\text { Zhanjiang }\end{array}$ & None \\
\hline 2017 & $\begin{array}{l}\text { Guangzhou, Shenzhen, } \\
\text { Foshan, Dongguan, } \\
\text { Zhuhai, Zhongshan, } \\
\text { Huizhou }\end{array}$ & $\begin{array}{l}\text { Jiangmen, Qingyuan, } \\
\text { Shaoguan }\end{array}$ & $\begin{array}{l}\text { Chaozhou, Heyuan, Jieyang, } \\
\text { Maoming, Meizhou, Shantou, } \\
\text { Shanwei, Yangjiang, Yunfu, } \\
\text { Zhanjiang, Zhaoqing }\end{array}$ & None \\
\hline
\end{tabular}
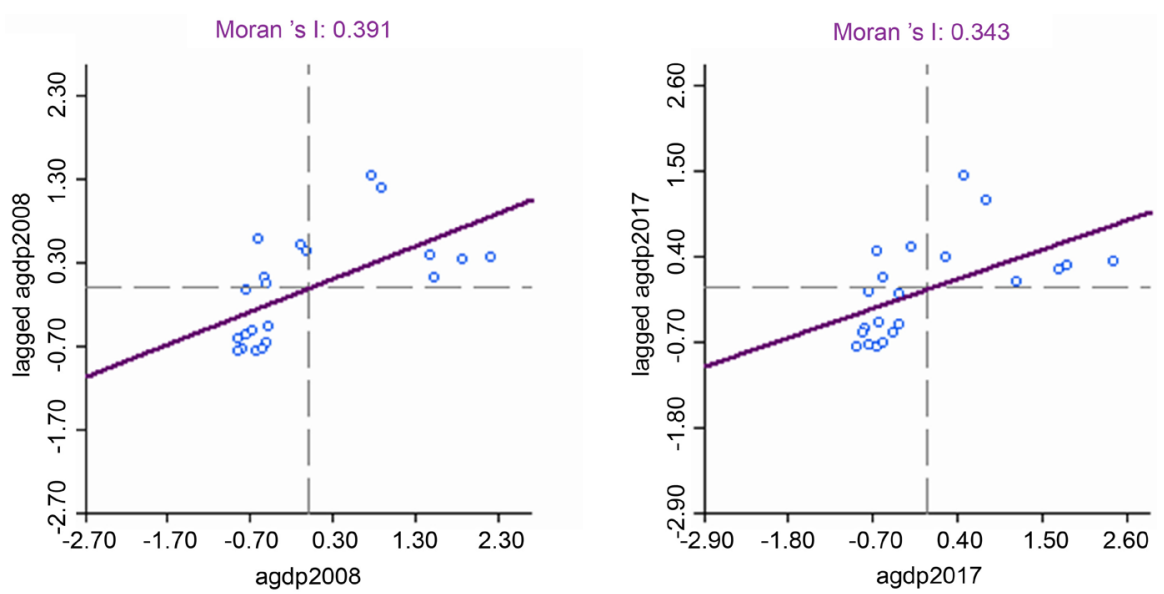

Figure 1. Moran 's I scatterplot of GDP per capita of 21 cities.

scatter plots of the local Moran's I in 2008 and 2017. Among them, the cities in the first quadrant belong to the high-high type. It means that the city has a relatively high economic development level, and most of the neighboring cities are also cities with high economic development levels. The cities in the third qua- 
drant belong to the low-low type. It means its own economic level is low, and the economic level of neighboring cities is also low. It can be seen that the cities in the first quadrant are often the Pearl River Delta cities, and the cities in the third quadrant are the traditional mountainous, eastern and western cities of Guangdong Province. This type of aggregation is the high-high type and the low-low type. It is a strong proof that the regional economic development level in Guangdong Province has a significant spatial correlation.

\section{Spatial Durbin Model}

This model is based on the Spatial Durbin Model and the Cobb-Douglas production function, and the variables are logarithmically processed and set as follows:

$$
\begin{aligned}
& \operatorname{In} A G D P=\rho W \operatorname{In} A G D P+\beta_{1} \operatorname{InRD}+\beta_{2} \operatorname{InPat}+\beta_{3} \operatorname{InInv}+\beta_{4} \operatorname{InStr}+\beta_{5} \operatorname{InGov} \\
& +\beta_{6} \operatorname{InUrb}+\beta_{7} \operatorname{InLab}+\beta_{8} \operatorname{InFdi}+\theta_{1} W \operatorname{In} R D+\theta_{2} W \operatorname{InPat}+\theta_{3} W \operatorname{InInv}(5) \\
& +\theta_{4} W I n S t r+\theta_{5} \text { WInGov }+\theta_{6} W I n U r b+\theta_{7} W I n L a b+\theta_{8} W I n F d i+\varepsilon
\end{aligned}
$$

where $\rho$ is the spatial autocorrelation coefficient, $W$ is the spatial weight matrix, $\beta$ and $\theta$ are the coefficients of the spatial lag term of the explanatory variable and the spatial lag term of the explanatory variable, and $\varepsilon$ is the random error term.

\subsection{Test Spatial Econometric Model}

In order to further ensure the rationality of the spatial econometric model, this paper uses the Lagrange multiplier form of LM test and the robust form of R-LM test to test the model. If the statistic passes the significance test, it indicates that there is spatial interaction. When all the tests pass, it indicates that the spatial econometric model should be introduced. The test results are shown in Table 3. It can be seen that the LM test can pass at the significance level of 0.05 . The three tests for spatial error reject the null hypothesis of no spatial autocorrelation, and the LM statistic in the spatial lag also rejects the null hypothesis. These results indicate that the spatial econometric model would be useful.

Table 3. Test results of various related tests.

\begin{tabular}{ccc}
\hline Method & Statistics & $p$ \\
\hline LM test-Spatial error & 40.579 & 0.000 \\
Robust LM test-Spatial error & 29.257 & 0.000 \\
LM test-Spatial lag & 11.887 & 0.001 \\
Robust LM test-Spatial lag & 0.565 & 0.452 \\
Hausman test (sigmamore) & 25.06 & 0.0015 \\
Hausman test (sigmaless) & 27.49 & 0.0006 \\
LR test-Spatial error & 26.13 & 0.0010 \\
LR test-Spatial lag & 27.1 & 0.0007 \\
\hline
\end{tabular}


Later, in order to determine the applicability of the Spatial Durbin Model, the LR test is also required. When the statistic passes the significance test, it indicates that the Spatial Durbin Model will not degenerate into a Spatial Lag Model or a Spatial Error Model. Spatial Durbin Model should be used in the empirical analysis. The results of the LR test are shown in Table 3. It can be seen that the LR statistic can be passed at the significance level of 0.05 , rejecting the assumption of the degradation of the Spatial Durbin Model.

After confirming the Spatial Durbin Model for empirical analysis, the Hausman test still needs to be performed. The Hausman test is used to determine whether a random effect or fixed-effect model needs to be used. Because the traditional Hausman statistic is negative, the paper will use the modified Hausman statistic. The test results are shown in Table 3. It can be seen that the revised two Hausman statistic $p$ is less than 0.01 , which can reject the original hypothesis of random effects. Therefore, this article uses the fixed effect model.

\subsection{Estimation Results of Spatial Durbin Model}

The fixed effect model is divided into three types: spatial fixed-effect model, time effect model and double fixed-effect model. This paper fits the three fixed-effect models separately, and the results are shown in Table 4. It can be seen from the results that in any effect model, the explanatory variables InPat and InRD have a

Table 4. SDM regression analysis results of three different effects.

\begin{tabular}{cccc}
\hline Variables & Time effect model & Spatial fixed effect model & Double fixed effect model \\
\hline InPat & $0.1300887^{* * *}$ & $0.0553905^{* *}$ & $0.050194^{* *}$ \\
InRD & $0.1421308^{* * *}$ & $0.0322706^{* * *}$ & $0.0322794^{* * *}$ \\
InInV & 0.0530719 & $-0.0215789^{* *}$ & 0.0012097 \\
InStr & 0.0872653 & $-0.3434329^{* * *}$ & $-0.3490521^{* * *}$ \\
InGov & $0.2154808^{* *}$ & $0.1469415^{* * *}$ & $0.1343218^{* * *}$ \\
InUrb & 0.0638236 & 0.2327564 & 0.1869777 \\
InLab & $-0.423751^{* * *}$ & 0.1616251 & 0.0652629 \\
InFdi & $0.09634^{* * *}$ & -0.0144039 & -0.015923 \\
WInPat & $0.2397556^{*}$ & -0.0233773 & 0.0008296 \\
WInRD & $0.0081089^{*}$ & -0.0067151 & -0.0089617 \\
WInInV & $0.2261607^{* *}$ & 0.0406023 & 0.056075 \\
WInStr & $1.069308^{* * *}$ & $0.4959953^{* * *}$ & $0.224949^{*}$ \\
WInGov & $-0.4073495^{*}$ & $0.0945459^{*}$ & 0.0195363 \\
WInUrb & $-1.488852^{* * *}$ & $-0.4417915^{*}$ & $-0.5122468^{* *}$ \\
WInLab & $-0.1845799^{* *}$ & $-0.6233824^{* *}$ & $-0.5992882^{* *}$ \\
WInFdi & $0.0273923^{*}$ & $0.0478549^{* *}$ & 0.0294696 \\
$\rho \rho$ & $0.2100461^{* *}$ & $0.4615103^{* * *}$ & -0.0851744 \\
R 2 & 0.9339 & 0.9736 & 0.9344 \\
\hline
\end{tabular}


positive effect on the regional economic growth of the city, and they can all pass the test with a significance level of 0.05 . Since the R-squared of the three models is greater than 0.9 , but the explanatory variables and control variables in the time fixed effect can pass the test of significance level more, so the time fixed-effect model that can best explain the space spillover effect is used for analysis.

In the time fixed-effect model, the spatial coefficient $\rho=0.21$, which can pass the significance level of 0.05 , indicating that the spillover effect between regions is obvious, and the spillover effect within the region has a positive effect on the overall growth of the regional economy. The coefficients of InPat and InRD of the explanatory variables are both more than 0 , and both can pass the significance level of 0.01. Among them, the coefficients of InPat and WInPat are both more than 0 , indicating that the output of technological innovation has effectively stimulated the growth of the regional economy. It means that the effective output of technological innovation can liberate productivity, and has promoted local and neighboring cities to high quality economic transformation at the same time.

The coefficients of $\operatorname{In} R D$ and $W \operatorname{In} R D$ are also more than 0 . The explanation is that the development of scientific research needs to rely on good basic constructions, such as excellent talents and matching experimental environment, so the investment of $\mathrm{R} \& \mathrm{D}$ funds can not only stimulate the development of the high-tech industries, but also promote the development of the culture and education industries, thereby stimulating other industries in the local area. However, it is worth mentioning that the coefficient of WInRD is relatively small, which is caused by the imbalance of regional economic development in the province. The difference in economic strength or infrastructure between cities makes the development level of high-tech industries uneven. The competition effect of scientific research investment is not high, so the spillover effect of investment in scientific and technological innovation is less.

\subsection{Effect Decomposition of Spatial Durbin Model}

Because of the regression analysis of the spatial econometric model with the spatial weight matrix, the estimated coefficients of the explanatory variables and control variables are not only the direct effects on the explained variables, but the discussion of the size of the coefficients cannot reflect the actual effects and influences of the variables. The Spatial Durbin Model decomposes effects into direct effects, indirect effects, and total effects. The direct effect represents the influence of the explanatory variables and control variables of the region on the economic growth of the region. The indirect effect represents the influence of the explanatory variables and control variables of the region on the economic growth of neighboring regions. The effect of explanatory variables and control variables on the overall economic growth of the region, so the partial differential method is used to decompose the total spatial effect. The decomposition results are shown in Table 5. 
Table 5. Effect decomposition of explanatory variables and control variables.

\begin{tabular}{ccccccc}
\hline \multirow{2}{*}{ Variables } & \multicolumn{2}{c}{ Direct effect } & \multicolumn{2}{c}{ Indirect effect } & \multicolumn{2}{c}{ Total effect } \\
\cline { 2 - 7 } & Coef & $p$ & Coef & $p$ & Coef & $p$ \\
\hline InPat & 0.148647 & 0.006 & 0.325311 & 0.035 & 0.473958 & 0.003 \\
InRD & 0.142351 & 0.001 & 0.045426 & 0.474 & 0.187778 & 0.010 \\
InInV & 0.070317 & 0.418 & 0.2897204 & 0.022 & 0.3600378 & 0.017 \\
InStr & 0.150756 & 0.499 & 1.345495 & 0.003 & 1.496251 & 0.018 \\
InGov & 0.202033 & 0.046 & -0.4372592 & 0.148 & -0.2352261 & 0.539 \\
InUrb & -0.0292793 & 0.867 & -1.785841 & 0.010 & -1.81512 & 0.021 \\
InLab & -0.4543855 & 0.000 & -0.3369319 & 0.402 & -0.7913174 & 0.051 \\
InFdi & 0.0987472 & 0.003 & 0.058248 & 0.402 & 0.156995 & 0.038 \\
\hline
\end{tabular}

The direct effect of the output of technological innovation on growth of Real GDP per capita is 0.148647 , which is significant at the level of 0.01 ; the indirect effect is 0.325311 , which is significant at the level of 0.05 ; the total effect is 0.473958 , which is significant at the level of 0.01 . Explained in terms of economic significance, the output of technology innovation in this region increased by $1 \%$, which can drive economic growth of $0.149 \%$, and at the same time make the economy of neighboring regions grow by $0.325 \%$. The explanation is that the Pearl River Delta cities with high-quality output of technological innovation have vigorously developed high-tech industries and transferred supporting industries and some industries through effective economic transformation, so that relatively backward mountainous, eastern and western cities have gotten new development opportunities. The effective output of technological innovation can adjust the factor supply configuration, change the demand structure and improve production efficiency. Various mechanisms promote the optimization and upgrading of the regional economic structure, and eventually play a significant role in promoting the total effect.

The direct effect of $\mathrm{R} \& \mathrm{D}$ expenditure on the growth of Real GDP per capita is 0.142351 , which is significant at the level of 0.01 ; the indirect effect is 0.045426 , which cannot pass the test of significance level. Explained in terms of economic significance, the region's investment in scientific and technological innovation increased by $1 \%$, which can promote economic growth of $0.142 \%$, it has a positive but unobvious effect on the economic growth of neighboring areas. This situation is consistent with the direction described by the coefficient of the Spatial Durbin Model. Due to the imbalance of regional economic development, there is a gap in the development of high-tech, cultural and education industries between cities. Cities that increase investment in scientific research and innovation are often economic. Cities with relatively strong strength and eager to seek economic transformation can attract more high-tech industries to settle locally through the increase of investment, and at the same time can attract high-quality talents and funds to come, so it is conducive to local economic development. 
The geographical proximity makes the siphon effect of developed areas crowd out the scientific research and innovation resources of backward areas. Although it can promote the economic growth of neighboring areas through the effective distribution of production factors and the effective use of labor, it also inhibits industries in backward areas to some extent. The ability to upgrade and innovate has weakened the endogenous power of the economic growth rate. Eventually, the indirect effect on backward areas is not obvious although it has a positive effect. From the perspective of total effect, the increase in investment in scientific and technological innovation by $1 \%$ can promote economic growth of $0.188 \%$, and it is significant at the level of 0.01 , indicating that the increase in investment in scientific research and innovation is to liberate regional productivity, and through the market and the labor and other mechanisms allocate resources such as production factors to achieve regional economic transformation, and therefore can promote the total economic growth of the region.

In terms of control variables, the direct effects of fixed capital input, industrial structure, and urbanization level are not significant, but the indirect effects and total effects are both significant at the level of 0.05 , and the coefficient of indirect effects is large, indicating that the spillover effect on neighboring cities is larger. The direct effects of government expenditure, labor and the degree of opening to the outside world are significant at the level of 0.05 , while the indirect effects are not significant. Among them, the total effect of government expenditure is not significant, because Guangdong Province has experienced a mature market economy since the economic development of reform and open up, and there are many special economic areas and high levels of opening up, so that the government's macro-control cannot excessively affect economic growth, but can only play the role of auxiliary and wind vane. Combining the analysis of the urbanization level and the labor level, we can see that the indirect effect of the urbanization level is negative. The increase in the urbanization level is negative for the economic development of neighboring cities, while the direct effect of the labor level is negative. It shows that there is a surplus of labor, which indicates that the excessively rapid urbanization process has promoted the siphon effect on the surrounding labor in the developed regions, but excessive labor cannot be well configured. On the contrary, it hinders the development of regional economy. The indirect effects of fixed asset investment and industrial structure also indicate that economic transformation and the development of high-tech industries are beneficial to neighboring cities and regions as a whole.

\section{Conclusions and Enlightenments}

Based on the research of relevant scholars and panel data of various cities in Guangdong Province, this paper studies the effect of input and output of technological progress on regional economic growth. First of all, by calculating the Moran's I in Guangdong Province, whether there is spatial correlation and spatial agglomeration, then the Spatial Durbin Model is established to consider the 
input and output of scientific and technological innovations and a series of related control variables on economic growth effect, and split this effect into direct effect, indirect effect and total effect. This paper mainly draws the following conclusions: 1) The Real GDP per capita level of the prefecture-level cities in Guangdong shows a spatial positive correlation, which is mainly manifested as the high-high and the low-low agglomeration types. The areas that are mutually reinforcing in economic development are mainly in the Pearl River Delta region, and relatively backward cities in the eastern, western and mountainous regions of Guangdong Province. It is worth mentioning that the low-high type cities are mainly distributed in the transition zone between economically developed areas and backward areas. Huizhou, which once belonged to the second quadrant type, became the first quadrant type after 10 years of development. It shows that the spatial spillover effect of the Pearl River Delta cities in the past decade is strong, and the dependence of the economic development of cities in Guangdong Province is increasing. 2) According to the empirical results of the Spatial Durbin Model, the output of technological progress can promote regional economic growth, and there is a significant positive spatial spillover effect. Although investment in scientific research and innovation does not affect the spatial spillover effect of neighboring cities obviously, but the direct effect and the total effect on the region are both significant and positive.

Therefore, these enlightenments should be taken into account. First, the government should optimize the spatial pattern of innovation capabilities of Guangdong and promote the coordinated development of urban agglomerations. Guangdong Province is an important space carrier for China to build a world-class urban agglomeration and participate in global competition. As Guangdong Province, which has an advantageous position in terms of economic scale and innovation capacity, the government should strengthen the innovation linkage between cities, reduce the gap of innovation in each city and promote the coordinated development of urban agglomerations. Second, the government should increase innovation input in Guangdong Province and introduce innovative talents. The funds and talents have a clear promotion effect on Guangdong's innovation capability. The government should formulate corresponding policies for innovation talents and funds to achieve the coordinated development of innovation capabilities. The most important of these is the rational distribution of regional innovative production factors. This reasonable industrial-structure should be based on the comprehensive environment of each city, including the innovative capital and innovative talents of each city. Therefore, talent pooling policies and differentiated innovation funding policies should be formulated. On the one hand, high-tech talent pooling should be encouraged, investment in research and development of high-tech enterprises should be increased, and new industries should be cultivated and developed. On the other hand, resources should be promoted to those cities with weaker innovation capabilities. Each city should increase cooperation and exchanges, promote the professionalization and divi- 
sion of labor in each city, and establish a multi-industry and cross-regional multi-investment system for R \& D. Finally, the government should establish an institution for innovation and development, whose main function is to evaluate the innovation capacity of each city, and to regulate and control different resources in cities with different innovation capabilities, so as to achieve a reasonable distribution of regional innovation production factors. In this way, inter-city coordination is strengthened during the formulation and implementation of various urban economic policies to effectively avoid the adverse effects of the vicious competition of scientific research and innovation on the overall regional economy.

\section{Conflicts of Interest}

The author declares no conflicts of interest regarding the publication of this paper.

\section{References}

[1] Lucas, R.E. (1988) On the Mechanics of Economic Development. Journal of Monetary Economics, 22, 3-42. https://doi.org/10.1016/0304-3932(88)90168-7

[2] Krugman, P. (1998) What's New about the New Economic Geography. Oxford Review of Economic Policy, 14, 7-17. https://doi.org/10.1093/oxrep/14.2.7

[3] Englmann, F. and Walz, U. (1995) Industrial Centers and Regional Growth in the Presence of Local Inputs. Journal of Regional Science, 35, 3-27. https://doi.org/10.1111/j.1467-9787.1995.tb01397.x

[4] Kubo, Y. (1995) Scale Economies Regional Externalities and the Possibility of Uneven Development. Journal of Regional Science, 35, 29-42. https://doi.org/10.1111/j.1467-9787.1995.tb01398.x

[5] Viladecansmarsal, E. (2004) Agglomeration Economies and Industrial Location: City-Level Evidence. Journal of Economic Geography, 4, 565-582. https://doi.org/10.1093/jnlecg/lbh040

[6] Avijit, D. and Niranjan, R. (2012) Testing Spillover Effects of Economic Growth: The Case of India's Northeastern Region. The IUP Journal of Applied Economics, 11, 84-92.

[7] Baudino, M. (2016) The Impact of Human and Physical Capital Accumulation on Chinese Growth after 1994: A Spatial Economic Approach. World Development Perspectives, 2, 11-16. https://doi.org/10.1016/j.wdp.2016.08.001

[8] Montmartin, B. and Herrera, M. (2015) Internal and External Effects of R\&D Subsidies and Fiscal Incentives: Empirical Evidence Using Spatial Dynamic Panel Models. Research Policy, 44, 1065-1079. https://doi.org/10.1016/j.respol.2014.11.013

[9] Qin, X.H., Du, D.B. and Kwan, M.-P. (2019) Spatial Spillovers and Value Chain Spillovers: Evaluating Regional R\&D Efficiency and Its Spillover Effects in China. Scientometrics, 119, 721-747. https://doi.org/10.1007/s11192-019-03054-7

[10] Buzard, K., Carlino, G.A., Hunt, R.M., Carr, J.K. and Smith, T.E. (2020) Localized Knowledge Spillovers: Evidence from the Spatial Clustering of R \& D Labs and Patent Citations. Regional Science and Urban Economics, 81, Article ID: 103490. https://doi.org/10.1016/j.regsciurbeco.2019.103490

[11] Motlagh, R.H., Babaee, A., Maleki, A. and Isaai, M.T. (2020) Innovation Policy, 
Scientific Research and Economic Performance: The Case of Iran. Development Policy Review, 38, 387-407. https://doi.org/10.1111/dpr.12423

[12] Zhou, B., Zeng, X.Y., Jiang, L. and Xue, B. (2020) High-Quality Economic Growth under the Influence of Technological Innovation Preference in China: A Numerical Simulation from the Government Financial Perspective. Structural Change and Economic Dynamics, 54, 163-172. https://doi.org/10.1016/j.strueco.2020.04.010

[13] Zhang, L. (2017) The Knowledge Spillover Effects of FDI on the Productivity and Efficiency of Research Activities in China. China Economic Review, 42, 1-14. https://doi.org/10.1016/j.chieco.2016.11.001

[14] Chen, Y.W., Yang, Z.P., Shu, F., Hu, Z.Y., Meyer, M. and Bhattacharya, S. (2008) A Patent Based Evaluation of Technological Innovation Capability in Eight Economic Regions in PR China. World Patent Information, 31, 104-110.

https://doi.org/10.1016/j.wpi.2008.06.010

[15] Xiong, A.L., Xia, S.M., Ye, Z.P., Cao, D.M., Jing, Y.G. and Li, H.Y. (2020) Can Innovation Really Bring Economic Growth? The Role of Social Filter in China. Structural Change and Economic Dynamics, 53, 50-61.

https://doi.org/10.1016/j.strueco.2020.01.003 